\title{
Kinetics of thiocyanate orientation conversion on Pt surface studied by in situ step-scan time-resolved microscope FTIR spectroscopy
}

\author{
ZHOU ZhiYou*, TIAN Na \& SUN ShiGang \\ State Key Laboratory for Physical Chemistry of Solid Surfaces, Department of Chemistry, College of Chemistry and Chemical Engineering, \\ Xiamen University, Xiamen 361005, China
}

Received March 13, 2012; accepted July 4, 2012; published online October 17, 2012

\begin{abstract}
Fast surface dynamic processes of thiocyanate adsorbed on a nanostructured Pt microelectrode were studied by in situ step-scan time-resolved microscope FTIR spectroscopy (in situ SSTR-MFTIRS) at a time resolution of $100 \mu$ s. It was found that $\mathrm{SCN}^{-}$adsorbs preferentially on Pt surface through $\mathrm{N}$ atom at low potential, while through $\mathrm{S}$ atom at high potential. The potential-induced orientation conversion between $\mathrm{N}$ - and S-bounded forms is very reversible, and occurs only within 2 ms after potential alternation. However, the rate constant $\left(4 \times 10^{3} \mathrm{~s}^{-1}\right)$ of conversion from $\mathrm{N}$ - to S-bounded adsorption is nearly double to that of the reverse process $\left(2 \times 10^{3} \mathrm{~s}^{-1}\right)$. The difference in kinetics of two processes may be explained through the hard-soft acid-base principle.
\end{abstract}

electrochemical in situ FTIRS, kinetics, $\mathrm{SCN}^{-}$, orientation conversion

Citation: Zhou Z Y, Tian N, Sun S G. Kinetics of thiocyanate orientation conversion on Pt surface studied by in situ step-scan time-resolved microscope FTIR spectroscopy. Chin Sci Bull, 2013, 58: 622-626, doi: 10.1007/s11434-012-5473-8

Thiocyanate $\left(\mathrm{SCN}^{-}\right)$has been extensively used as an electroplating additive, and also employed as a probe ion in surface science to study surface-adsorbate interactions and electrochemical double-layer structure due to its strong adsorption on metal surface [1-6]. Since the negative charges on $\mathrm{S}$ atom (-0.71 e) and $\mathrm{N}$ atom (-0.48 e) are comparable, the $\mathrm{SCN}^{-}$can bind on metal surface through either $\mathrm{N}$ or $\mathrm{S}$ atom [7]. As a result, there appear a variety of adsorption forms of $\mathrm{SCN}^{-}$, such as N-bounded (M-NCS), S-bounded (M-SCN) and bridge-bounded (M-SCN-M) adsorption [8,9], which can be distinguished from vibration frequency of the C-N stretch $\left(v_{\mathrm{C}-\mathrm{N}}\right)$, detected by IR or Raman spectroscopy [7]. The adsorption orientation of $\mathrm{SCN}^{-}$on the electrode surfaces usually can be converted to each other. For example, spectrochemical studies have shown that M-NCS can change to M-SCN as the potential shifts positively on the $\mathrm{Au}$ [10], Fe [11], and Pt electrodes [8,12,13]. The orientation conversion of $\mathrm{SCN}_{\mathrm{ad}}$ occurs quickly ( $\left.\mathrm{ms}\right)$, so its sur-

\footnotetext{
*Corresponding author (email: zhouzy@xmu.edu.cn)
}

face dynamic processes hardly can be monitored by conventional in situ IR and Raman techniques with low ( s) time resolution $[14,15]$.

Previously, we established an electrochemical in situ step-scan time-resolved microscope FTIR spectroscopy (in situ SSTR-MFTIRS) with a time resolution as fast as $10 \mu \mathrm{s}$ [16]. Herein, by using this advanced technique, we successfully monitored surface dynamic processes of orientation conversion of $\mathrm{SCN}_{\mathrm{ad}}$ on Pt surface, and obtained the kinetic parameters of orientation conversion.

\section{Experimental}

\subsection{In situ SSTR-MFTIRS measurements}

The setup and principle of in situ SSTR-MFTIRS was reported in detail previously [16]. It consists of a Nexus 870 FTIR spectrometer with step-scan facility (Nicolet, USA), an IR microscope (IR-Plan ${ }^{\circledR}$ Advantage, Spectra-Tech Inc., USA), a home-made signal synchronizer and a thin-layer IR 
cell working with a microelectrode. The reactions studied by step-scan FTIR spectroscopy should be very repeatable, since they need occur thousands of times. The time-resolved spectra are calculated as the relative change in reflectivity by using following formula:

$$
\frac{\Delta R\left(t_{i}\right)}{R}=\frac{R\left(E_{\mathrm{S}, t_{i}}\right)-R\left(E_{\mathrm{R}}\right)}{R\left(E_{\mathrm{R}}\right)},
$$

where $R\left(E_{\mathrm{R}}\right)$ and $R\left(E_{\mathrm{S}, t_{i}}\right)$ are single-beam spectra collected respectively at the reference potential $\left(E_{\mathrm{R}}\right)$ and at the sample potential $\left(E_{\mathrm{S}}\right)$ along with the course of time evolution.

\subsection{Preparation of nanostructured $\mathrm{Pt}$ microelectrode and thiocyanate adsorption}

The constructions of the thin-layer IR cell and the Pt microelectrode $(\phi=200 \mu \mathrm{m})$ were also reported previously [16]. The counter and reference electrodes were Pt wire and saturated calomel electrode (SCE), respectively. All electrode potentials reported here were quoted versus the SCE scale. To improve the IR determination sensitivity, the polished $\mathrm{Pt}$ microelectrode was subjected to a treatment of $10 \mathrm{~Hz}$ square wave potential between -0.27 and $1.30 \mathrm{~V}$ in $0.1 \mathrm{~mol} / \mathrm{L}$ $\mathrm{H}_{2} \mathrm{SO}_{4}$ for $40 \mathrm{~min}$ [17]. Such treatment can generate nanostructured Pt film on the surface [17], which exhibits abnormal infrared effects (AIREs), i.e. the direction of IR bands of adsorbate is reversed and the band intensity is enhanced by several ten times $[18,19]$. The enhanced absorption can improve greatly the signal to noise ratio of spectra. This nanostructured $\mathrm{Pt}$ microelectrode is denoted thereafter as nm-PtME.

Adsorption of $\mathrm{SCN}^{-}$on the nm-PtME was carried out in $5 \times 10^{-3} \mathrm{~mol} / \mathrm{L} \mathrm{NaSCN}+0.5 \mathrm{~mol} / \mathrm{L} \mathrm{NaClO}_{4}$ solution. It was reported that the coverage of $\mathrm{SCN}^{-}$adsorbed on Pt surface is saturated as the $\mathrm{SCN}^{-}$concentration in the solution exceeds $1 \times 10^{-3} \mathrm{~mol} / \mathrm{L}$ [9]. Finally, the nm-PtME was pressed towards $\mathrm{CaF}_{2}$ IR window to form a thin layer solution $(\sim 10$ $\mu \mathrm{m})$ to reduce the intensive absorption by water.

\section{Results and discussion}

\subsection{Cyclic voltammetric studies}

Figure 1 shows cyclic voltammograms $(\mathrm{CVs})$ of nm-PtME in $5 \times 10^{-3} \mathrm{~mol} / \mathrm{L} \mathrm{NaSCN}+0.5 \mathrm{~mol} / \mathrm{L} \mathrm{NaClO}_{4}$ solution (solid line). The potential was scanned negatively from 0.00 to $-1.10 \mathrm{~V}$, and then scanned positively at $100 \mathrm{mV} / \mathrm{s}$. Clearly, the current is featureless from -1.0 to $0.50 \mathrm{~V}$, i.e. only typical charging/discharging current of double-layer capacitance, which is similar to that reported previously [4]. The onset potential for the oxidation of $\mathrm{SCN}^{-}$species is about $0.50 \mathrm{~V}$ (inset to Figure 1). Two current peaks appear at around 0.70 and $1.12 \mathrm{~V}$. To identify these two current peaks, $\mathrm{CVs}$ of nm-PtME with pre-adsorbed $\mathrm{SCN}^{-}$in the $0.5 \mathrm{~mol} / \mathrm{L}$ $\mathrm{NaClO}_{4}$ solution were also recorded, and the first two cycles

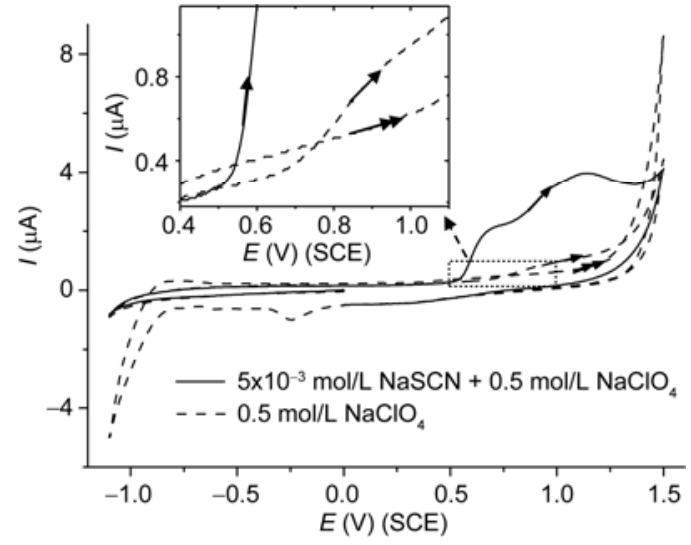

Figure $1 \mathrm{CVs}$ of nm-PtME in $5 \times 10^{-3} \mathrm{~mol} / \mathrm{L} \mathrm{NaSCN}+0.5 \mathrm{~mol} / \mathrm{L} \mathrm{NaClO}_{4}$ solution (solid line), and with pre-adsorbed $\mathrm{SCN}^{-}$in $0.5 \mathrm{~mol} / \mathrm{L} \mathrm{NaClO}_{4}$ solution (dashed line). The inset is the magnification near the onset potential. Scan rate: $100 \mathrm{mV} / \mathrm{s}$

are also shown in Figure 1 (dashed line). In the potential range from -1.1 to $0.50 \mathrm{~V}$, the $\mathrm{CV}$ of pre-adsorbed $\mathrm{SCN}_{\mathrm{ad}}$ in the first cycle is superposed with that obtained in $5 \times 10^{-3}$ $\mathrm{mol} / \mathrm{L}$ NaSCN solution, indicating that both coverages are the same. In the magnified curves near the onset potential (inset to Figure 1), it can be observed that pre-adsorbed $\mathrm{SCN}_{\mathrm{ad}}$ begins to be oxidized at about $0.60 \mathrm{~V}$, but its oxidation current is much lower than that obtained in the $5 \times 10^{-3}$ $\mathrm{mol} / \mathrm{L} \mathrm{NaSCN}$. This result indicates that the two current peaks observed in $5 \times 10^{-3} \mathrm{~mol} / \mathrm{L} \mathrm{NaSCN}$ solution mainly come from the oxidation of solution $\mathrm{SCN}^{-}$ions. The products of oxidation of thiocyanate reported are very complex, including $\mathrm{SO}_{4}{ }^{2-}, \mathrm{CN}^{-}, \mathrm{OCN}^{-}, \mathrm{CO}_{2}, \mathrm{NO}_{2}^{-}{ }^{-}[20]$.

\subsection{Steady-state FTIR spectroscopic studies}

Prior to the test of in situ SSTR-MFTIRS, it needs to explore the potential region where $\mathrm{SCN}_{\mathrm{ad}}$ orientation conversion can occur very reversibly. Figure 2(a) shows the steady-state FTIR spectra on nm-PtME in $5 \times 10^{-3} \mathrm{~mol} / \mathrm{L}$ $\mathrm{NaSCN}+0.5 \mathrm{~mol} / \mathrm{L} \mathrm{NaClO}_{4}$ solution. Reference spectrum was collected at $1.40 \mathrm{~V}$, where the $\mathrm{SCN}_{\mathrm{ad}}$ had been oxidized completely [9]. Sample potential varied from -1.10 to 0.00 $\mathrm{V}$ at an interval of $0.10 \mathrm{~V}$, and then back to $-1.10 \mathrm{~V}$. Similar to the previous IR result [12], only one band at around $2100 \mathrm{~cm}^{-1}$ can be observed in the $1900-2300 \mathrm{~cm}^{-1}$ region. This band can be assigned to the $v_{\mathrm{C}-\mathrm{N}}$ of $\mathrm{SCN}_{\mathrm{ad}}$, since it exhibits significant Stark effects: band center shifts from 2084 to $2120 \mathrm{~cm}^{-1}$ as the potential increases from -1.10 to $0.00 \mathrm{~V}$. The band intensity of $v_{\mathrm{C}-\mathrm{N}}\left(I_{\mathrm{C}-\mathrm{N}}\right)$ decreases gradually with increasing potential, which is also similar to the previous report [12]. From the $\mathrm{CV}$ results (Figure 1), we know that $\mathrm{SCN}_{\mathrm{ad}}$ can not be oxidized significantly below $0.60 \mathrm{~V}$, so the decrease in $I_{\mathrm{C}-\mathrm{N}}$ can not be assigned to the oxidation of $\mathrm{SCN}_{\mathrm{ad}}$. Generally, the infrared absorptivity of adsorbates observed in electrochemical in situ FTIR spectra 

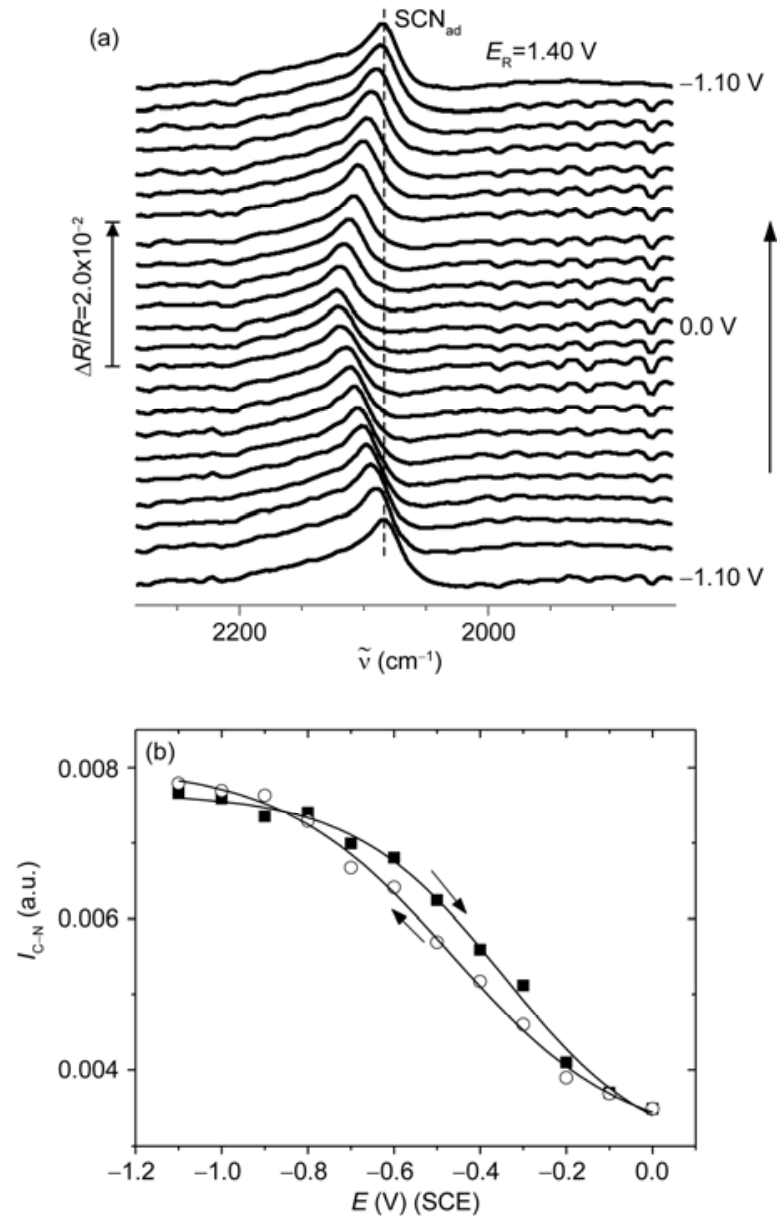

Figure 2 (a) Steady-state FTIR spectra of $\mathrm{SCN}^{-}$absorbed on nm-PtME at different potential in $5 \times 10^{-3} \mathrm{~mol} / \mathrm{L} \mathrm{NaSCN}+0.5 \mathrm{~mol} / \mathrm{L} \mathrm{NaClO} 4.8 \mathrm{~cm}^{-1}$, 400 scans, potential was changed from -1.10 to $0.0 \mathrm{~V}$ at an interval of 0.10 $\mathrm{V}$, then back to $-1.10 \mathrm{~V} ; E_{\mathrm{R}}$ was $1.4 \mathrm{~V}$. (b) Potential dependence of band intensity of $v_{\mathrm{C}-\mathrm{N}}$.

is independent on electrode potential given a consistent coverage and fixed adsorption orientation. Therefore, the decrease in $I_{\mathrm{C}-\mathrm{N}}$ with potential is unlikely attributed to the effect of electrode potential on the absorptivity of $\mathrm{SCN}_{\mathrm{ad}}$. As for SCN-metal complexes, it has been reported that the absorptivity of $v_{\mathrm{C}-\mathrm{N}}$ in $\mathrm{N}$-ligand forms is significantly larger than that of $v_{\mathrm{C}-\mathrm{N}}$ in S-ligand forms [21,22]. Therefore, the decreasing $I_{\mathrm{C}-\mathrm{N}}$ with increasing potential previously was attributed to the change of the $\mathrm{SCN}_{\mathrm{ad}}$ adsorption orientation from $\mathrm{N}$-bounded to $\mathrm{S}$-bounded form $[4,8,12]$. The failed observation of two IR bands for two SCN forms may be correlated with the dipole-dipole interaction of adsorbed $\mathrm{SCN}_{\mathrm{ad}}$. Unlike SERS, electrochemical in situ FTIR spectroscopy is difficult to detect $\mathrm{Pt}-\mathrm{S}$ and $\mathrm{Pt}-\mathrm{N}$ bonds located in the far-infrared region [6]. In addition, it was even observed that the co-adsorption of $\mathrm{N}$ - and S-bounded SCN on the Au surfaces can yield two SERS bands of $v_{\mathrm{C}-\mathrm{N}}$, while only one IR band can be observed [6].

It can be observed that the evolution of the IR band of $\mathrm{SCN}_{\mathrm{ad}}$ with potential alternation in Figure 2(a) is quite re- versible. The reversibility can be further comfirmed by the analysis of the potential dependence of peak-height band intensity $\left(I_{\mathrm{C}-\mathrm{N}}\right)$ of $v_{\mathrm{C}-\mathrm{N}}$, as shown in Figure 2(b). Although metal-adsorbate stretching vibrations $\left(v_{\mathrm{Pt}-\mathrm{N}}\right.$ and $\left.v_{\mathrm{Pt}-\mathrm{S}}\right)$, the straightforward criterion of adsorption orientation, are inaccessible from the IR spectroscopy, the potentialdependent $I_{\mathrm{C}-\mathrm{N}}$ can provide some evidences. As shown in Figure $2(\mathrm{~b})$, the $I_{\mathrm{C}-\mathrm{N}}$ in both forward and backward processes decrease gradually with increasing potential, and then trend to a constant, in good agreement with sigmoid growth curve fitting (solid lines), two stable values at two potential limits. This result suggests that $\mathrm{N}$-bounded $\mathrm{Pt}_{-\mathrm{NCS}}$ ad dominated at $-1.0 \mathrm{~V}$ in the present conditions, while S-bounded Pt-SCN $\mathrm{Sd}_{\mathrm{ad}}$ at $0.0 \mathrm{~V}$. Evidently, the potential- induced orientation conversion of $\mathrm{SCN}_{\mathrm{ad}}$ is fairly reversible in the potential region between -1.10 and $0.00 \mathrm{~V}$. It was found that the reversibility decreases when the potential is higher than $0.10 \mathrm{~V}$. This may be attributed to the oxidation and removal of some $\mathrm{SCN}_{\mathrm{ad}}$.

\subsection{Dynamic studies of orientation conversion by SSTR-MFTIRS}

Figure 3(a) shows in situ SSTR-MFTIR spectra of $\mathrm{SCN}_{\mathrm{ad}}$ orientation conversion on the nm-PtME in $5 \times 10^{-3} \mathrm{~mol} / \mathrm{L}$ $\mathrm{NaSCN}+0.5 \mathrm{~mol} / \mathrm{L} \mathrm{NaClO}_{4}$ solution, triggered by potential
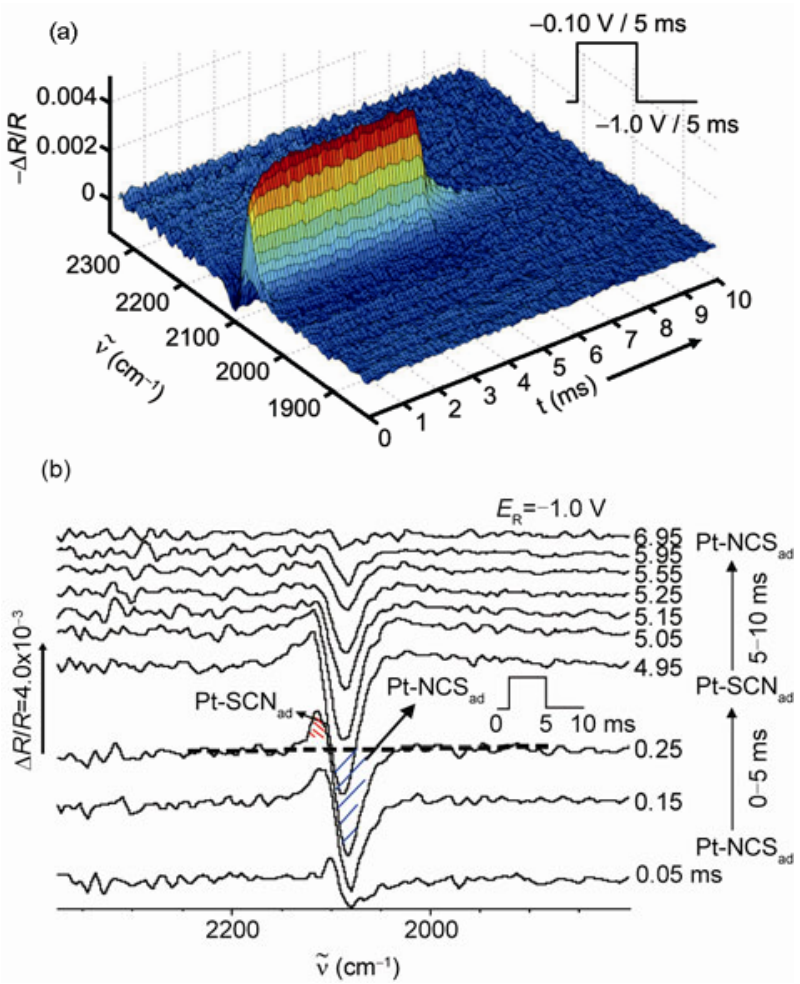

Figure 3 (a) 3D plot of SSTR-MFTIRS and (b) some typical spectra of $\mathrm{SCN}_{\mathrm{ad}}$ orientation conversion on nm-PtME in $5 \times 10^{-3} \mathrm{~mol} / \mathrm{L} \mathrm{NaSCN}+0.5$ $\mathrm{mol} / \mathrm{L} \mathrm{NaClO}_{4}$. Potential stepping from -1.0 to $-0.10 \mathrm{~V}$, then back to -1.0 $\mathrm{V}$ after $5 \mathrm{~ms}$; time resolution was $100 \mu \mathrm{s} ; 8 \mathrm{~cm}^{-1}, 200$ scans. 
alternating between -0.10 and $-1.0 \mathrm{~V}$. The time resolution was $100 \mu$ s. Note that the $Z$ axis in Figure 3(a) is inversed (i.e. $-\Delta R / R$ ) to clearly display the $3 \mathrm{D}$ figure. To show the IR band shapes more clearly, some typical spectra were extracted and shown in Figure 3(b). At $0.0 \mathrm{~ms}$, the potential was stepped from -1.0 to $-0.10 \mathrm{~V}$ to trigger the conversion from Pt-NCS ${ }_{\mathrm{ad}}$ to $\mathrm{Pt}-\mathrm{SCN}_{\mathrm{ad}}$; after $5 \mathrm{~ms}$, the potential was stepped back to $-1.0 \mathrm{~V}$ to trigger the inverse process. The static spectrum collected at $-1.0 \mathrm{~V}$ was used as the reference spectrum. At $-1.0 \mathrm{~V}, \mathrm{Pt}-\mathrm{NCS}_{\mathrm{ad}}$ is dominated on the surface, whose IR band is located at low wavenumbers and exhibits stronger absorption than those of $\mathrm{Pt}-\mathrm{SCN}_{\mathrm{ad}}$ at -0.1 $\mathrm{V}$, as indicted by the steady-state spectra (Figure 2). Therefore, the resulting time-resolved spectra are expected to be the asymmetric bipolar bands, and the stronger lobe at low wavenumbers comes from the Pt-NCS ${ }_{\mathrm{ad}}$ [3]. Although the total measurement time needed about $3 \mathrm{~h}$ (the reaction repeatedly occurred for about $2.7 \times 10^{5}$ times), it was found that the $\mathrm{SCN}_{\mathrm{ad}}$ was quite stable and the decrease in $I_{\mathrm{C}-\mathrm{N}}$ was less than $10 \%$ after the SSTR-MFTIR measurement.

In the initial $5 \mathrm{~ms}$, a bipolar band quickly grows, and then trends to stable within $2 \mathrm{~ms}$. This corresponds to the dynamic process of orientation conversion from Pt-NCS $\mathrm{Ad}_{\mathrm{ad}}$ to Pt-SCN ${ }_{\mathrm{ad}}$. In the 5-10 ms, the inverse process occurs, and the bipolar band decreases with time, and then trends to zero. The SSTR-MFTIR spectra clearly indicate that the orientation conversion of $\mathrm{SCN}_{\mathrm{ad}}$ on Pt surface occurs very fast, and the reaction time is within $2 \mathrm{~ms}$. Besides, there is no perceptible bridge-bounded $\mathrm{SCN}_{\mathrm{ad}}$ (i.e. Pt-SCN-Pt) around $-2200 \mathrm{~cm}^{-1}$ [9], one possible intermediate of orientation conversion.

Through quantitative analysis of the spectral data, we can obtain the kinetic parameters of orientation conversion of $\mathrm{SCN}_{\mathrm{ad}}$. Figure 4(a) shows the time dependence of the $I_{\mathrm{C}-\mathrm{N}}$ and transient current ( $i$ - $t$ curve) recorded simultaneously. The calculation method of the $I_{\mathrm{C}-\mathrm{N}}$ is illustrated in Figure 3 (b), i.e. the area above the baseline (red shadow) minus that below the baseline (blue shadow) was selected to evaluate the conversion processes. We did not select the sum area of two regions, because it contains the contribution generated from the potential-induced frequency shift, which also results in a bipolar peak even without the conversion. In the $0-5 \mathrm{~ms}, I_{\mathrm{C}-\mathrm{N}}$ decreases sharply with time, and one order exponential decay function can be used to fit well these experimental data. The fitting result (solid line) can be described by the following equation:

$$
I_{\mathrm{C}-\mathrm{N}}=-0.125\left(1-\exp \left(-\frac{t}{0.26 \pm 0.02}\right)\right),
$$

where a time constant of $0.26 \pm 0.02 \mathrm{~ms}\left(\tau_{N \rightarrow S}\right)$ has been evaluated.

Similarly, the $I_{\mathrm{C}-\mathrm{N}}$ variation in the $5-10 \mathrm{~ms}$ time region can be fitted as eq. (3):

$$
I_{\mathrm{C}-\mathrm{N}}=-0.121 \exp \left(-\frac{t-5.0}{0.47 \pm 0.03}\right),
$$

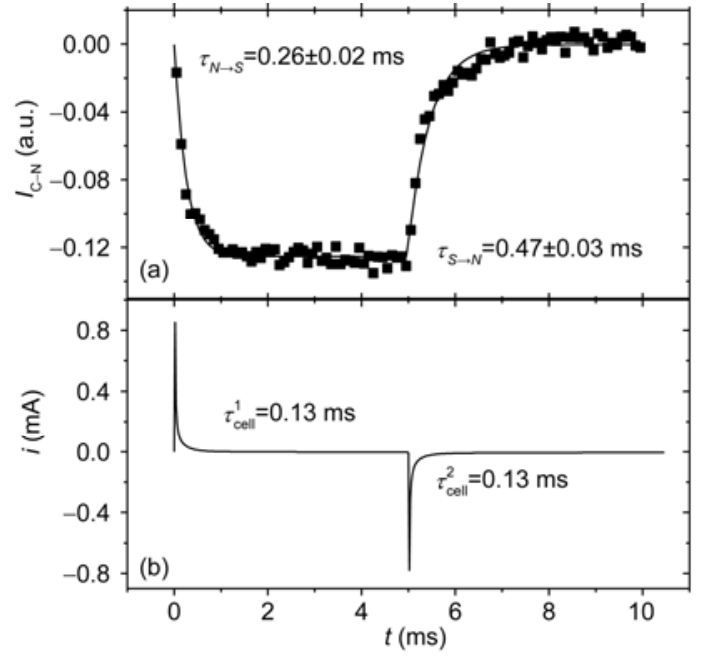

Figure 4 Time-dependence of integral band intensity of $v_{\mathrm{C}-\mathrm{N}}$ (a) and transient current (b) during orientation conversion of $\mathrm{SCN}_{\mathrm{ad}}$.

where a time constant of $0.47 \pm 0.03 \mathrm{~ms}\left(\tau_{S \rightarrow N}\right)$ can be obtained.

The time constants of IR cell $\left(\tau_{\text {cell }}\right)$, a parameter to reflect the time for double-layer charging, was both $0.13 \mathrm{~ms}$ (Figure 4(b)) based on $i$ - $t$ curve. The $\tau_{\text {cell }}$ was smaller, but comparable to $\tau_{N \rightarrow S}$ and $\tau_{S \rightarrow N}$ yet. Although $\tau_{\text {cell }}$ may be slightly shortened by further reducing the microelectrode diameter or by increasing the thickness of thin-layer solution, these methods can lower the IR determination sensitivity and increase the calculation errors of $\tau_{N \rightarrow S}$ and $\tau_{N \rightarrow S}$ (eqs. (2) and (3)). In the present experiment, it is very hard to further shorten $\tau_{\text {cell }}$ significantly. Despite the $\tau_{\text {cell }}$ can not be neglected in comparison with $\tau_{N \rightarrow S}$ or $\tau_{S \rightarrow N}$, we can still obtain the semi-quantitative rate constants of $\mathrm{SCN}_{\mathrm{ad}}$ orientation conversion, which are somewhat smaller than the real values. On basis of eqs. (2) and (3), the rate constants of orientation conversion from Pt-NCS $\mathrm{Nd}_{\mathrm{ad}}$ to Pt-SCN at $-0.10 \mathrm{~V}$ was $4 \times 10^{3} \mathrm{~s}^{-1}$, and the inverse process at $-1.0 \mathrm{~V}$ was $2 \times 10^{3} \mathrm{~s}^{-1}$. Clearly, the reaction rate of the former was nearly double to that of the latter.

The difference in reaction kinetics might be correlated with the interactions between Pt and ligand atoms. Based on hard-soft acid-base (HSAB) principle, the $\mathrm{N}$ (small and relatively unpolarizable) and $\mathrm{S}$ atoms in $\mathrm{SCN}^{-}$ions are assigned to hard and soft base, respectively, and $\mathrm{Pt}^{2+}$ to soft acid [23]. As predicted by theoretical calculation of HSAB principle [24,25], the reaction between hard-acid and hard-base is controlled by charge interaction (or electrostatic interactions), which occurs very quickly; the reaction between soft-acid and soft-base is controlled by frontier orbitals, in which the energy levels of highest occupied molecular orbital (HOMO) and lowest unoccupied molecular orbital (LUMO) are very close, so that the interaction is also quickly. That is, the kinetic of the hard-hard or soft-soft 
reactions is faster than that of the hard-soft combination. In our study, the orientation conversion from Pt-NCS ${ }_{\mathrm{ad}}$ to Pt-SCN ${ }_{\mathrm{ad}}$ corresponds to the decomposition of "soft acid $\left(\mathrm{Pt}^{\delta+}\right)$-hard base ( $\mathrm{N}$ atom in $\left.\mathrm{SCN}^{-}\right)$", and the formation of "soft acid $\left(\mathrm{Pt}^{\delta+}\right)$-soft base ( $\mathrm{S}$ atom in $\left.\mathrm{SCN}^{-}\right)$". The reactivity of soft-soft should be faster than that of soft-hard as predicted by the HSAB principle. This is consistent with our observation: the rate of Pt-NCS ${ }_{\mathrm{ad}}$ to $\mathrm{Pt}-\mathrm{SCN}_{\mathrm{ad}}$ (hard-soft $\rightarrow$ soft-soft, fast) is double that of reverse process (soft-soft $\rightarrow$ hard-soft, slow).

\section{Conclusions}

Surface dynamic processes of potential-induced orientation conversion of adsorbed $\mathrm{SCN}^{-}$on Pt surface were illustrated by in situ SSTR-MFTIRS at molecular level. It was found that the processes occur quickly, only within $2 \mathrm{~ms}$. The rate constants of orientation conversion from Pt-NCS $\mathrm{Sd}_{\mathrm{ad}}$ to $\mathrm{Pt}_{-} \mathrm{SCN}_{\mathrm{ad}}$ at $-0.10 \mathrm{~V}$ was $4 \times 10^{3} \mathrm{~s}^{-1}$, while that of the reverse process at $-1.0 \mathrm{~V}$ was only $2 \times 10^{3} \mathrm{~s}^{-1}$. The results demonstrate that in situ SSTR-MFTIRS is a powerful tool for studying fast surface dynamic processes and kinetics of electrochemical reactions.

This work was supported by the National Natural Science Foundation of China (21073152, 20833005, 20933004, and 21021002), the Fundamental Research Funds for the Central Universities (2010121021 and 2012121019), Program for New Century Excellent Talents in University (NECT-11-0301) and Outstanding Young Scientific Talents Cultivation Plan of Colleges in Fujian Province (JA10003).

1 Schlesinger M, Paunovic M. Modern Electroplating. 4th ed. New York: John Wiley \& Sons, 2000

2 Magnussen O M. Ordered anion adlayers on metal electrode surfaces. Chem Rev, 2002, 102: 679-726

3 Ashley K, Weinert F, Feldheim D L. Infrared-spectroscopy to probe the electrochemical double-layer. Electrochim Acta, 1991, 36: 1863-1868

4 Ashley K, Samant M G, Seki H, et al. Cation effects on the vibrational frequencies of adsorbed thiocyanate on platinum. J Electroanal Chem, 1989, 270: 349-364

5 Niu T C, Yuan Y X, Wang M, et al. Surface enhanced Raman spectroscopic studies of the adsorption of thiocyanate at Pt electrode inionicliquids (in Chinese). Chem J Chin Univ-Chin, 2008, 29: 22452248

6 Li J F, Huang Y F, Ding Y, et al. Shell-isolated nanoparticle-enhanced Raman spectroscopy. Nature, 2010, 464: 392-395

7 Bailey R A, Kozak S L, Michelsen T W, et al. Infrared spectra of complexes of the thiocyanate and related ions. Coord Chem Rev,
1971, 6: 407-445

8 Luo H, Weaver M J. Surface-enhanced Raman scattering as a versatile vibrational probe of transition-metal interfaces: Thiocyanate coordination modes on platinum-group versus coinage-metal electrodes. Langmuir, 1999, 15: 8743-8749

9 Tian Z Q, Ren B, Mao B W. Extending surface Raman spectroscopy to transition metal surfaces for practical applications. 1. Vibrational properties of thiocyanate and carbon monoxide adsorbed on electrochemically activated platinum surfaces. J Phys Chem B, 1997, 101: 1338-1346

10 Li X, Gewirth A A. Potential-dependent reorientation of thiocyanate on Au electrodes. J Am Chem Soc, 2003, 125: 11674-11683

11 Cao P, Yao J L, Ren B, et al. Potential dependence of the orientation of thiocyanate adsorbed on an iron electrode as probed by surface-enhanced Raman spectroscopy. J Phys Chem B, 2002, 106: 7283-7285

12 Bron M,Holze R. Polarization sensitive in situ infrared spectroscopy: The adsorption of simple ions at platinum electrodes. Fresenius $\mathbf{J}$ Anal Chem, 1998, 361: 694-696

13 Zhang B, Li J F, Zhong Q L, et al. Electrochemical and surfaced-enhanced Raman spectroscopic investigation of $\mathrm{CO}$ and SCNadsorbed on Au-core-Pt-shell nanoparticles supported on GC electrodes. Langmuir, 2005, 21: 7449-7455

14 Chen J G, Li W H, Liao Y Y, et al. New collection lens system of Raman spectrometer for electrochemical time-resolved Raman measurements (in Chinese). Chin J Light Scattering, 1996, 8: 54-58

15 Tian Z Q, Li W H, Mao B W, et al. Potential-averaged surface-enhanced Raman spectroscopy. Appl Spectrosc, 1996, 50: 1569-1577

16 Zhou Z Y, Lin S C, Chen S P, et al. In situ step-scan time-resolved microscope FTIR spectroscopy working with a thin-layer cell. Electrochem Commun, 2005, 7: 490-495

17 Chen Y J, Sun S G, Chen S P, et al. Anomalous IR properties of nanostructured films created by square wave potential on an array of Pt microelectrodes: An in situ microscope FTIRS study of $\mathrm{CO}$ adsorption. Langmuir, 2004, 20: 9920-9925

18 Lu G Q, Sun S G, Cai L R, et al. In situ FTIR spectroscopic studies of adsorption of $\mathrm{CO}, \mathrm{SCN}^{-}$, and poly (o-phenylenediamine) on electrodes of nanometer thin films of $\mathrm{Pt}, \mathrm{Pd}$, and $\mathrm{Rh}$ : Abnormal infrared effects (AIREs). Langmuir, 2000, 16: 778-786

19 Gong H, Sun S G, Chen Y J, et al. In situ microscope FTIRS studies of $\mathrm{CO}$ adsorption on an individually addressable array of nanostructured Pt microelectrodes-An approach of vombinatorial analysis of anomalous IR properties. J Phys Chem B, 2004, 108: 11575-11584

20 Nicholson M M. Voltammetry of thiocyanate ion at the stationary platinum electrode. Anal Chem, 1959, 31: 128-132

21 Pecile C. Infrared studies of planar and tetrahedral inorganic thiocyanates. Inorg Chem, 1966, 5: 210-214

22 Fronaeus S, Larsson R. Studies on metal complexes in aqueous solution by infrared spectrophotometry. 3. Further investigations on thiocyanato complexes. Acta Chem Scand, 1962, 16: 1447

23 Pearson R G. Hard and soft acids and bases. J Am Chem Soc, 1963, 85: 3533-3539

24 Klopman G. Chemical reactivity and the concept of charge- and frontier-controlled reactions. J Am Chem Soc, 1968, 90: 223-234

25 Koch E C. Acid-base interactions in energetic materials: 1. The hard and soft acids and bases (HSAB) principle-Insights to reactivity and sensitivity of energetic materials. Propellants Explos Pyrotech, 2005, 30: 5-16

Open Access This article is distributed under the terms of the Creative Commons Attribution License which permits any use, distribution, and reproduction in any medium, provided the original author(s) and source are credited. 